\title{
Conflict of interest disclosure: striking a balance?
}

\author{
Livio Garattini ${ }^{1} \cdot$ Anna Padula $^{1}$
}

Published online: 3 January 2019

c) Springer-Verlag GmbH Germany, part of Springer Nature 2019

\section{Introduction}

Conflicts of interest (CoI) have always been part of human beings' daily life since ever and a permanent concern in legal affairs [1]. The most common definition of CoI is a situation where individuals must choose between the duties of their jobs and their own private interests [2]. Therefore, individuals very frequently have potential CoI within their organizations [3].

CoI have become a hotly debated concept in the scientific literature during the last few decades in medicine too [4]. Although many definitions have been proposed [5], the core of the first one-issued by Thompson in [6] and adopted by the WHO [7] - is still the most cited. Accordingly, CoI are 'a set of conditions in which professional judgment concerning a primary interest tends to be unduly influenced by a secondary interest'. While primary interests refer to the main goals of the profession/activity (e.g. patient's welfare or scientific research), secondary ones can include financial gains and personal motives (e.g. interpersonal relationships and professional prestige, or desire to favor family and friends) [8]. CoI are not per se synonymous with professional misconduct and compromised integrity $[1,9]$. They simply exist whether or not an individual is actually influenced by them [10], raising a risk that professional judgment may be compromised by secondary interests [11].

CoI are potentially ubiquitous in medicine [12], virtually affecting all aspects. They have been analyzed for biomedical [13] and clinical [14] research, medical education [15] and patient fundraising [16], publications in scientific journals [17, 18], health care [5] and clinical [19] guidelines.

Disclosure is the most frequent and straightforward strategy used to manage $\mathrm{CoI}$ in professional life [11] — at least the first essential step for addressing them [15]. CoI disclosure

Livio Garattini

livio.garattini@marionegri.it

1 Centre for Health Economics, CESAV, Institute for Pharmacological Research Mario Negri IRCCS, 24020 Ranica, Italy has become common practice in scientific congresses and publications [20], although variously managed by journals [21] and still lacking in many published articles [13]. In some organizations CoI disclosure has been extended even to small gifts from industry to health professionals [22].

Here, first we summarize the main features of the ongoing debate on CoI in the health literature, focusing on the two types (financial, non-financial) and the two rival narratives (critical, defensive). Then we discuss their limits and draw our conclusion on the CoI debate.

\section{Two types}

The debate on CoI in health originally stemmed from financial interests and then expanded to non-financial ones-two very different types of CoI that imply different management and are best analyzed separately [23].

Financial CoI have repeatedly eroded the credibility of medical profession and scientific journals [10], especially those involving payments from the pharmaceutical industry [4]. In principle, financial CoI are easy to identify and thus can be easily disclosed. They can bias the results in any kind of research activity [24], even when the methods are valid (e.g. by framing the study question), therefore, they demand attention and their disclosure is important [25]. Sometimes the size of payments to individuals is impressive [26], although judgment on them depends on their type too. For instance, large payments to physicians from companies may be considered differently, whether they are for royalties on inventions or for talks in congresses. In general, the level of interest is essential to assess a potential CoI [8]. Of course, large financial interests of organizations and individuals should be declared [27], but the real dilemma is where to set the limit for small sums received from industry. Common sense suggests that this limit is in fact subjective, depending on a country's level of wealth too, and situational, varying by culture and history [28].

Non-financial CoI are a broad category, difficult to define, measure and manage [18]. Most non-financial CoI cannot 
be separated from the individuals concerned [9], potentially dealing with private interests of professional, ideological or religious nature; family relationships, friendships and personal rivalries. Even the mere disclosure of some of them may raise ethical and privacy issues [23]. Since any individual has friends or enemies and specific interests in a topic or field, the bias direction of this type of $\mathrm{CoI}$ can be predicted by knowledge of them [24]. For instance, an editor can invite a referee on purpose to peer review a manuscript since s/he knows her/his interests [27]. This implies an ethical concern for both the editor and the referee, and any expert must strive to be as objective as possible [20]. Of course, non-financial interests intrinsically affect research activity and can bias results, but cannot necessarily be considered secondary interests [23]. Many disagreements led by intellectual interests have historically moved the sciences forward [25]. Social scientists have long contended that researchers cannot be fully impartial or disinterested in any field, by definition, and data are unlikely to be the only 'driver' of conclusions in all sciences [24].

Despite the intrinsic differences which recommend not mixing the two types of CoI, most organizations (e.g. regulatory agencies, journals, guideline committees) have increasingly managed them with similar strategies [23].

\section{Two narratives}

The multidisciplinary debate on $\mathrm{CoI}$ has led to two opposite narratives in health literature, marked by either critical or defensive positions and a dismissive attitude towards each other [4].

The critical discourse is dominant in the literature, mainly backed by evidence-based studies and individual case reports from rigorous scholars, policy makers, journalists, and sometimes whistle-blowers. According to them-nicknamed 'pharmascolds' by their opponents-health professionals and organizations are unavoidably influenced by financial relationships with industry, often unconsciously and unintentionally [29], and this can lead to individual and institutional corruption. Since the primary goal of industry representatives is to promote their products-not to secure patients' interests - the best tactic for health professionals should be to avoid them [22]. Even meals and small gifts paid by industry are considered somehow morally blameworthy [30]. Raising any avoidable CoI on purpose does not respect the medical obligation to earn and honor the patient's trust, so their disclosure is not considered enough, and avoidance and divestment should be the preferred approach.

On the other side, the defensive discourse is mainly supported through counterarguments and criticisms of the dominant narrative by physicians, researchers and consultants with industry ties [4]. According to these-nicknamed 'pharmapologists' by their opponents- $\mathrm{CoI}$ are empirically meaningless and driven by ideology against medical science [31]. Since almost any kind of interest can raise a potential conflict [27], the critical approach of pharmascolds makes CoI unhelpfully ubiquitous and the current web of moral insinuations lead to the opposite result of their main goal [31], i.e. to preserve public trust in medicine and science. Since the primary interest of medical science-to benefit patients-mainly coincides with individual interests, the term 'conflict' itself is pejorative and presumptive of inappropriate behavior [32]. Therefore, it should be removed and (for instance) replaced by 'confluence', to suggest an alignment between primary and secondary interests.

The only point on which the two discourses implicitly agree is that commerce and marketing play a major role in contemporary health care and medical science, while there is profound disagreement on their consequences [4]. Pharmascolds seem sceptical about the capitalist philosophy, while pharmapologists implicitly believe in the positive role of the 'invisible hand of free market' in constraining bad industry practices in the long run.

\section{Discussion}

CoI are a moral issue of human nature in general, definitely not limited to health professionals [29]. The only individuals without $\mathrm{CoI}$ are probably those who know nothing about the primary interest at issue [33], CoI are potentially ubiquitous and any attempt to 'eradicate' them is meaningless.

The number of scientific publications addressing the CoI concept in health has substantially increased during recent decades (Fig. 1), and there still seems to be a long way to go to achieve a dialectical synthesis of this debate

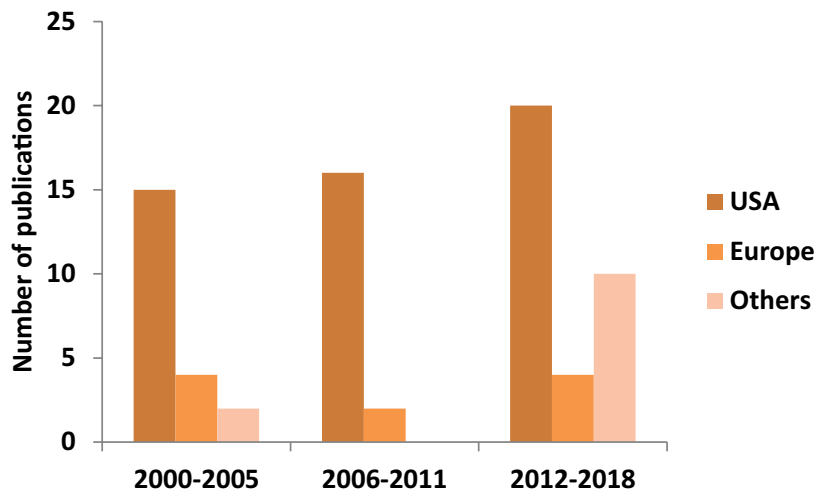

Fig. 1 Articles with 'conflict of interest' in their title, focused on health care. We searched the PubMed international database to select studies with 'conflict of interest' in their title, focused on health care, published in English since January 2000. From the 89 articles initially identified, 16 were discarded, being: legal cases (7); letters (5); news (4). We finally selected 73 studies 
[4]. The majority of publications $(>70 \%)$ come from the US, probably not by chance, since the American health system has the highest prevalence of private 'players' (both for funding and provision) among highly developed countries [34], and health care expenditure is permanently out of control [35]. Last but not least, many American companies of pharmaceuticals and medical devices are big and profitable. Pharmapologists even contend that pharmascolds, despite the same 'gene pool', seem to oppose the positive concept of 'profit' which marks American culture [31].

As is typical in the 'Americanization' of debates [36], a point missing at the onset is that health care is a classical example of market failure in economic theory, since health is a 'merit good' rather than a common 'consumer good' [37]. This justifies the 'principal-agent' role played by physicians with patients in deciding therapies and that of third-party payers in mainly funding health expenses. Then, differently from hospital services, most drugs and medical devices in developed countries are supplied by private companies, by definition, profit-oriented [38]. However, this does not lead on to the economic paradigm of 'free market' for health products, and in fact they require strict regulation all over the world.

Financial CoI are widespread in health care. Setting a 'threshold' below which a payment does not have to be declared as a financial $\mathrm{CoI}$ is a problematic exercise-if not impossible. Rather, it seems more important to make disclosure compulsory on the basis of payment, without limiting this to health professionals - as happens in many countries [39]. For instance, funding for publications in journals and speeches in congresses related to specific drugs and devices should be declared by all decision-makers and experts involved in health care, no matter the amount. Since a private for-profit company is not expected to pay an expert for a study or a speech that goes against its product, the presence of sponsorship is highly predictive of a positive opinion, regardless of the rigorousness of methods. For instance, we reviewed the pharmacoeconomic studies based on Markov models and found they almost always concluded in favor of the sponsored drug (with a risk of error $<1 \%$ ) [40], and disclosure of financial CoI was crucial to conduct our analysis.

In general, we noticed that narratives focused only on financial CoI of physicians raised by industry payments (small gifts and meals included), while completely overlooking those raised by physicians' dual practice (i.e. the combination of public and private practice) [41]. Paraphrasing the title of a commentary [9], this seems to us a 'big elephant in the room to decloak' in the era of patient empowerment [42]. If patients' interests are the cornerstone of their fiduciary relationship with physicians [22], and business ethics must not be mixed with medical ethics [43], dual practice can definitely undermine patients' medical trust; therefore, it should be at least mentioned as a primary source of financial $\mathrm{CoI}$ in most countries.

There is no reason to assume that non-financial $\mathrm{CoI}$ are peculiar to health care more than to other fields, since experts have their own personal expectations, professional interests and beliefs in any sort of activity. Some non-financial CoI should be more carefully detected in organizations like scientific societies and universities (e.g. family relationships to avoid nepotism), others should not (e.g. religious faith to avoid discrimination). However, they cannot be necessarily considered $\mathrm{CoI}$ and their management depends largely on the current ethics of countries-level of corruption included. We can just note again that intellectual interests are part of any scientific debate and inevitably emerge in comments. For instance, referring to our previous example of pharmacoeconomic models, our opinion that they are of scant utility for pricing and reimbursing drugs because of their intrinsic limits-so even when public agencies use them-clearly emerges in our articles on this subject [37, 38, 44].

\section{Comment}

We are convinced that the primary deterrents of $\mathrm{CoI}$ are knowledge and criticism, and the 'ethical must' of all experts should be to pursue objectivity striving to minimize their personal interests (intellectual ones included) [20].

Except for negligible payments, full transparency on financial $\mathrm{CoI}$ is a priority in health, drawing attention to the risk of bias [23]. Although by definition transparency cannot provide any guidance for resolving bias [13], rejecting it for financial CoI would be a major mistake [45]. Instead, mandatory disclosure of non-financial CoI risks being confounding and even arguable in some cases, paradoxically distracting attention from the real bias potentially raised by financial CoI.

Finally, we declare that this commentary stemmed from our own intellectual interest in better understanding the hot debate on $\mathrm{CoI}$ in health care. We wonder now what further theoretical arguments might be added by CoI experts to improve this debate. We feel the main practical effort from now on should be to detect daily the correct disclosure by experts of (non-negligible) financial $\mathrm{CoI}$ in all health care settings.

Funding No sources of funding were used to conduct this study or prepare this manuscript.

\section{Compliance with ethical standards}

Conflict of interest Anna Padula and Livio Garattini have no conflicts of interest directly relevant to this article. 


\section{References}

1. Annane, D., Charpentier, B.: Do I have a conflict of interest? Yes. Intensive Care Med. 44(10), 1741-1743 (2018)

2. Gupta, A., Holla, R., Suri, S.: Conflict of interest in public health: should there be a law to prevent it? Indian J. Med. Ethics 12(3), 172-177 (2015)

3. Clark, J.R.: Conflict of interest. Air. Med. J. 36(4), 160-161 (2017)

4. Purdy, S., Little, M., Mayes, C., Lipworth, W.: Debates about Conflict of Interest in Medicine: deconstructing a divided discourse. J. Bioeth. Inq. 14(1), 135-149 (2017)

5. Morciano, C., Basevi, V., Faralli, C., Hilton Boon, M., Tonon, S., Taruscio, D.: Policies on conflicts of interest in health care guideline development: a cross-sectional analysis. PLoS One 11(11), e0166485 (2016)

6. Thompson, D.F.: Understanding financial conflicts of interest. N. Engl. J. Med. 329(8), 573-576 (1993)

7. World Health Organization. Handbook for guideline development, (2014). Available: http://www.who.int/kms/handbook_2nd_ed.pdf Last access: September 2018

8. Frybourg, S., Remuzat, C., Kornfeld, A., Toumi, M.: Conflict of interest in health technology assessment decisions: case law in France and impact on reimbursement decisions. J. Mark. Access Health Policy 3(1), 25682 (2015)

9. Ruble, J.H.: Tools for "decloaking" the elephant in the room: conflict of interest, shared decision-making, and patient-centered care. J. Pain Palliat. Care Pharmacother. 29(2), 173-177 (2015)

10. Steinbrook, R., Kassirer, J.P., Angell, M.: Justifying conflicts of interest in medical journals: a very bad idea. BMJ 350, h2942 (2015)

11. Mayes, C., Lipworth, W., Kerridge, I.: Declarations, accusations and judgement: examining conflict of interest discourses as performative speech-acts. Med. Health Care Philos. 19(3), 455-462 (2016)

12. Bauchner, H., Fontanarosa, P.B., Flanagin, A.: Conflicts of interests, authors, and journals: new challenges for a persistent problem. JAMA. 320(22), 2315-2318 (2018)

13. Dunn, A.G., Coiera, E., Mandl, K.D., Bourgeois, F.T.: Conflict of interest disclosure in biomedical research: a review of current practices, biases, and the role of public registries in improving transparency. Res. Integr. Peer Rev. 1, 1 (2016)

14. Horton, R.: Conflicts of interest in clinical research: opprobrium or obsession? Lancet 349(9059), 1112-1113 (1997)

15. Lo, B., Ott, C.: What is the enemy in CME, conflicts of interest or bias? JAMA 310(10), 1019-1020 (2013)

16. Collins, M.E., Rum, S.A., Sugarman, J.: Navigating the ethical boundaries of grateful patient fundraising. JAMA 320(10), 975976 (2018)

17. Bauchner, H., Fontanarosa, P.B., Flanagin, A., Thornton, J.: Scientific misconduct and medical journals. JAMA. 320(19), 19851987 (2018)

18. Menkes, D.B., Masters, J.D., Bröring, A., Blum, A.: What does 'unpaid consultant' signify? a survey of euphemistic language in conflict of interest declarations. J. Gen. Intern. Med. 33(2), 139-141 (2018)

19. Shekelle, P.G.: Clinical practice guidelines: what's next? JAMA 320(8), 757-758 (2018)

20. Wernerman, J.: Do i have a conflict of interest? Not sure. Intensive Care Med. 44(10), 1746-1747 (2018)

21. Bosch, X., Pericas, J.M., Hernández, C., Doti, P.: Financial, nonfinancial and editors' conflicts of interest in high-impact biomedical journals. Eur. J. Clin. Invest. 43(7), 660-667 (2013)
22. Kelly, T.: Conflicts about conflict of interest. Camb. Q. Healthc. Ethics 25(3), 526-535 (2016)

23. Bero, L.: Addressing bias and conflict of interest among biomedical researchers. JAMA 317(17), 1723-1724 (2017)

24. Bero, L., Grundy, Q.: Why having a (nonfinancial) interest is not a conflict of interest. PLoS Biol. 14(12), e2001221 (2016)

25. Lenzer, J.: When is a point of view a conflict of interest? BMJ 355, i6194 (2016)

26. Lo, B., Grady, D.: Payments to physicians: does the amount of money make a difference? JAMA 317(17), 1719-1720 (2017)

27. Vincent, J.L., Christopher, K.B., McLean, A.: Do i have a conflict of interest? No. Intensive Care Med. 44(10), 1744-1745 (2018)

28. Fineberg, H.V.: Conflict of Interest: why does it matter? JAMA 317(17), 1717-8 (2017)

29. Gold, A., Appelbaum, P.S.: Unconscious conflict of interest: a Jewish perspective. J. Med. Ethics 37(7), 402-405 (2011)

30. Brody, H.: Clarifying conflict of interest. Am J Bioeth 11(1), 23-28 (2011)

31. Stossel, T.P.: Divergent views on managing clinical conflicts of interest. Mayo Clin Proc. 82(8), 1013-1014 (2007)

32. Cappola, A.R., FitzGerald, G.A.. Confluence: Not conflict of interest: name change necessary. JAMA 314(17), 1791-1792 (2015)

33. Smith, R.: Conflict of interest and the BMJ. BMJ 308(6920), 4-5 (1994)

34. Garattini, L., Padula, A.: Competition in health markets: is something rotten? J. R. Soc. Med. (2018). https://doi. org/10.1177/0141076818816935

35. Fuchs, V.R.: How to make US health care more equitable and less costly. JAMA. 320(20), 2071-2072 (2018)

36. Powell, M., Béland, D., Waddan, A.: The Americanization of the British National Health Service: a typological approach. Health Policy 122(7), 775-782 (2018)

37. Garattini, L., Padula, A.: Competition in pharmaceuticals: more product-than price-oriented? Eur. J. Health Econ. 19(1), 1-4 (2018)

38. Garattini, L., Padula, A.: Pharmaceutical pricing conundrum: time to get rid of it? Eur. J. Health Econ. 19(8), 1035-1038 (2018)

39. Grundy, Q., Habibi, R., Shnier, A., Mayes, C., Lipworth, W.: Decoding disclosure: comparing conflict of interest policy among the United States, France, and Australia. Health Policy 122(5), 509-518 (2018)

40. Garattini, L., Koleva, D., Casadei, G.: Modeling in pharmacoeconomic studies: funding sources and outcomes. Int J Technol. Assess Health Care 26, 330-333 (2010)

41. Garattini, L., Padula, A.: Dual practice of hospital staff doctors: hippocratic or hypocritic? J. R. Soc. Med. 111(8), 265-269 (2018)

42. Garattini, L., Padula, A.: Patient empowerment in Europe: is no further research needed? Eur. J. Health Econ 19(5), 637-640 (2018)

43. Misselbrook, D.: Fighting about conflict of interest: where should the balance lie? Br J Gen Pract 66(643), 66-67 (2016)

44. Garattini, L., Padula, A.: Dutch guidelines for economic evaluation: 'from good to better' in theory but further away from pharmaceuticals in practice? J. R. Soc. Med. 110(3), 98-103 (2017)

45. Wilson, M.: Is transparency really a panacea? J. R. Soc. Med. 107(6), 216-217 (2014)

Publisher's Note Springer Nature remains neutral with regard to jurisdictional claims in published maps and institutional affiliations. 